PLEASE NOTE:

This is the author's version of the manuscript accepted for publication in Journal of GLBT Family Studies. Changes resulting from the publishing process, namely editing, corrections, final formatting for printed or online publication, and other modifications resulting from quality control procedures, may have been subsequently added.

The published version can be found in: Freitas, D., D'Augelli, A. R., Coimbra, S., \& Fontaine, A. M. (2016). Discrimination and mental health among gay, lesbian, and bisexual youths in Portugal: The moderating role of family relationships and optimism. Journal of GLBT Family Studies, 12(1), 68-90. doi: 10.1080/1550428X.2015.1070704 
Discrimination and Mental Health among Gay, Lesbian, and Bisexual Youths in Portugal: The Moderating Role of Family Relationships and Optimism Daniela F. Freitas, Anthony R. D’Augelli, Susana Coimbra, and Anne Marie Fontaine Authors' Information

Daniela F. Freitas, Faculty of Psychology and Education Sciences of the University of Porto, Portugal, and Ribeirão Preto School of Philosophy, Science and Literature of the University of São Paulo, Brazil.

Anthony R. D’Augelli, College of Health and Human Development, Pennsylvania State University, University Park, Pennsylvania, USA.

Susana Coimbra, Faculty of Psychology and Education Sciences of the University of Porto, Portugal.

Anne Marie Fontaine, Faculty of Psychology and Education Sciences of the University of Porto, Portugal.

Correspondence concerning this article should be addressed to Daniela Freitas, Faculdade de Psicologia e de Ciências da Educação da Universidade do Porto, Rua Alfredo Allen 4200-135, Porto, Portugal. E-mail: daniela.ffreitas@gmail.com

Acknowledgements: This work was supported by a doctoral grant awarded to the first author by the FCT - the Portuguese Foundation for Science and Technology (SFRH/BD/79575/2011) and by the International Students' USP Grant Program (2014.1.3765.1.1) 


\begin{abstract}
This study investigates associations between mental health, perception of discrimination (unfair treatment and personal rejection), family environment dimensions - satisfaction, intimacy, admiration, and conflict in the relationships with the mother and the father, and familial optimism - in a sample of 84 gay, lesbian, and bisexual (GLB) Portuguese adolescents. Results show that participants with higher levels of mental health experience less discrimination, feel more respected by their fathers, have fewer conflicts with both parents, and belong to families with higher levels of optimism. No significant differences were found with regard to satisfaction and intimacy in the relationships with both parents and in the perception of admiration by the mothers. Conflict with parents moderated the relation between discrimination and mental health. Having frequent experiences of conflict with parents was found to exacerbate the negative impact of occasional acts of discrimination on mental health. Results highlight the relevance of a positive family environment as a protection mechanism in the face of discrimination, and the need to lower the levels of homophobia and heterosexism in social contexts, in order to promote GLB adolescents well-being.
\end{abstract}

Keywords: victimization, protection mechanisms, familial optimism, parental admiration, conflict with parents 
Discrimination and Mental Health among Gay, Lesbian, and Bisexual Youths in Portugal: The Moderating Role of Family Relationships and Optimism

Adolescence is a life period marked by an array of psychosocial changes. One central task of this developmental period concerns identity consolidation. A process of individuation from parents begins and parent-child relationships tend to become more egalitarian by the end of adolescence. Peer relationships become more intimate and supportive. Individuals start dating and investing in romantic relationships (Smetana, Campione-Barr, \& Metzger, 2006). In this developmental period, gay, lesbian, and bisexual (GLB) youths face particular challenges beyond those also faced by their heterosexual counterparts (D’Augelli, 1998; Rivers \& Carragher, 2003). Developing a non-heterosexual identity requires the confrontation with its social stigmatization (Floyd \& Stein, 2002; Meyer, 2003). Given these particular challenges, recent research has been addressing protective factors as well as resilient trajectories in the lives of individuals belonging to sexual minorities (Beasley, Jenkins, \& Valenti, 2015; Saewyc, 2011). Resilience can be defined as positive adaptation, under significant adversity (Coimbra, 2008; Luthar, Cicchetti, \& Becker, 2000; Masten \& Reed, 2002). For a resilient trajectory to occur, effects of risk mechanisms are to be avoided, buffered or diminished by protection mechanisms, resulting in a positive adaptation (Coimbra, 2008; Fergus \& Zimmerman, 2005; Luthar, Cicchetti, \& Becker, 2000). Given the reported negative impact of social prejudice on the mental health of sexual minorities (Saewyc, 2011), in this study we explored how family relationships - satisfaction, intimacy, admiration and conflict with the mother and the father - and familial optimism may foster mental health in Portuguese GLB youths. 
Studies have documented lower levels of mental health among sexual minority youths, when compared with their heterosexual counterparts (D’Augelli, 2002; Espelage, Aragon, Birkett, \& Koenig, 2008). A part of the differences that have been found regarding mental health may be explained by direct experiences of homophobic related violence. In fact, GLB youths suffer more lifetime victimization than their heterosexual counterparts, and are more likely to be victims of bullying at school (Fedewa \& Ahn, 2011; Katz-Wise \& Hyde, 2012). D'Augelli (2002), in a study of GLB North American youths, found that $81 \%$ of participants reported having been verbally insulted and $38 \%$ were physically threatened during their lifetimes. In Portugal, a study using a convenience sample found that half (49\%) of gay/lesbian and about one-third (35\%) of bisexual youths reported some form of homophobic victimization at school (António, Pinto, Pereira, Farcas \& Moleiro, 2012). Furthermore, a study of discrimination against sexual minority adults showed that $67 \%$ have "been prevented from doing something, been hassled or made feel inferior" at least one time during their lifetime (Chae et al., 2010, p. 593).

It is noteworthy that, even before the adolescents' coming out, parents and peers may react negatively to a possible atypical gender expression. In the D’Augelli, Grossman, and Starks' (2006) study, more than half of the GLB sample was signaled by others as being gender atypical when growing up, and seen as "different" by others around the age of eight. In this study, about one-third of the parents of adolescents who manifested gender atypicality discouraged behaviors considered to be "deviant" (typical of the opposite-sex). Thus, a gender expression considered non-normative puts children, adolescents, and adults at risk of victimization, regardless of their sexual orientation (e.g. D’Augelli et al., 2006; Elamé, 2013). Some studies suggest that youths can experience some same-sex attraction from 8 to 11 years of 
age, recognize themselves as GLB between 14 and 17, and disclose their sexual orientation to their parents between 15 to 19 years of age (D'Augelli, Grossman, \& Starks, 2008b; D'Augelli, Hershberger, \& Pilkington, 1998; D’Augelli, 2002; Savin-Williams \& Diamond, 2000). Thus, there is a considerable time gap between first gender atypicality manifestations (for some GLB individuals), first same-sex attraction, and the disclosure of sexual orientation. During this time range, studies show that youths may have already suffered multiple forms of victimization, both visible and silent, from peers and from parents (D'Augelli et al., 2006, 2008b).

Much research has been linking GLB youth victimization to higher levels of school truancy, depression, anxiety, suicide ideation and attempts, substance use, risky sexual behavior, and lower levels of self-esteem and life satisfaction (Bontempo \& D'Augelli, 2002; Eisenberg \& Resnick, 2006; Espelage et al., 2008; Fedewa \& Ahn, 2011; Feinstein, Goldfried, \& Davila, 2012; Russell, Ryan, Toomey, Diaz, \& Sanchez, 2011; Ueno, 2005). Additionally, some studies suggest that the negative impact of homophobia is long-lasting, resulting in more susceptibility to depression or post-traumatic stress in adulthood (Rivers, 2001, 2004; Russell, Toomey, Ryan, \& Diaz, 2014). Other factors that account for the poor mental health of GLB youths are associated with the need to cope with negative messages from the social context regarding nonheterosexuality, lower levels of social support from family, friends, and school staff, fear of losing friends following coming out, or negative reactions and rejection from parents (D'Augelli et al., 1998; D’Augelli, 2002; Fedewa \& Ahn, 2011; Meyer, 2003; Needham \& Austin, 2010; Robinson \& Espelage, 2012).

\section{Family Relationships and Mental Health}

As a primary source of socialization, the family plays a crucial role in adolescent development. Common sense suggests that conflict and detachment from parents increases 
during adolescence, and although research supports the idea that despite increasing conflict with parents, during adolescence, mothers and fathers continue to be a major source of affection (Lempers \& Clark-Lempers, 1992). Parents are regarded as important sources of instrumental help and stability, qualities that help youngsters to develop competencies conducive to gaining independence without fear of relationship break up (Lempers \& Clark-Lempers, 1992). Although a moderate level of conflict with parents in adolescence favors this process, having frequent conflicts with parents is associated with diminished well-being in adolescents (Smetana et al., 2006). Also, the gender of both parent and child seems to influence the way parent-child relationships evolve. For example, adolescents discuss more emotional matters, such as romantic relationships, with mothers, and more instrumental matters, such as careers, with fathers (Smetana et al., 2006). Concurrently, adolescents perceive warmer and more instrumental aid from the parent of the same-gender than from the different-gender parent (Lempers \& ClarkLempers, 1992; Shanahan, McHale, Crouter, \& Osgood, 2007).

Literature on resilience underlines the importance of positive, supportive, and close family relationships in fostering positive adjustment in face of adversity (Fergus \& Zimmerman, 2005; Leme, Del Prette, \& Coimbra, 2013; Luthar, Cicchetti, \& Becker, 2000; Resnick et al., 1997; Saewyc, 2011; Walsh, 2003). When youngsters face discrimination, certain qualities pertaining to family relational processes seem to mitigate the negative impact of this particular adversity. For instance, in a study regarding ethnic victimization, family cohesion buffered the negative impact of discrimination on anxiety (Juang \& Alvarez, 2010). However, parents who have GLB children have to face specific challenges. Knowing that a child is not heterosexual may be particularly stressful for parents; hence, they usually undergo a process of adaptation which may lead to changes in parent-child relationships (D’Augelli, 2005; LaSala, 2000; Savin- 
Williams \& Dubé, 1998). As previously mentioned, parents may come to act negatively toward their son/daughter even before the disclosure of his/ her sexual orientation, based on the observation of a non-normative gender expression and the associated fear, or assumption, of their child's non-heterosexuality. Moreover, there seems to be some constancy in parental attitudes. For instance, a retrospective Portuguese study evidenced a positive correlation between the experience of low care, hostility, and neglect by parents in childhood and negative parental reactions to the act of coming out (Oliveira, 2012). When youngsters reveal their nonheterosexuality to parents, again, some parents may react negatively and even violently (D’Augelli et al., 1998). Parental rejection of a non-heterosexual orientation has been linked to increased mental health problems, substance use, and suicide attempts (D’Augelli, 2002; Ryan, Huebner, Diaz, \& Sanchez, 2009). Studies also suggest that fathers may react more negatively, and be less accepting, when perceiving their child to be non-heterosexual. A higher percentage of fathers, when compared with mothers, manifested more negative reactions to gender atypicality during childhood and puberty (80\% vs. 25\%; D'Augelli et al. 2006), and were more intolerant (16\% vs. $9 \%)$ and rejecting (26\% vs. $10 \%)$ of their son's/daughter's sexual orientation after the its disclosure (D’Augelli et al., 1998).

When youngsters still live with their parents, parental influences are more pronounced and the negative impact of conflicts and other stresses can be even more stressful. Bebes, Samarova, Shilo, and Diamond (2015) found that negative parental control (e.g., withdrawal of affection when a behavior is disapproved) is associated with more psychological distress among GLB adolescents. Furthermore, negative parental control was found to have a more pronounced influence on GLB adolescents' psychological symptoms than parental acceptance (e.g., giving affection and making the child feel important) (Bebes et al., 2015). Thus, negative parental 
interaction, whether or not related to sexual orientation issues, can have a very negative effect on the mental health of GLB adolescents. Moreover, sexual minorities have been reported to have more serious arguments with their parents as compared with heterosexual youths, and, consequently, to experience higher levels of psychological distress (Ueno, 2005).

In contrast, studies also suggest that a significant number of GLB youths are doing well, have good relationships, and find support from teachers, friends, sexual minority communities and, in particular, from their families (D’Augelli, 2002; Hershberger \& D'Augelli, 1995; Murdock \& Bolch, 2005; Ryan, Russell, Huebner, Diaz, \& Sanchez, 2010; Saewyc, 2011). Positive attitudes towards sexual orientation and parental acceptance are positively related to higher levels of general health, self-esteem, sexual identity consolidation, social support, and lower levels of depression, substance use, and suicidal behavior (Floyd, Stein, Harter, Allison, \& Nye, 1999; Hershberger and D'Augelli, 1995; Ryan et al., 2010). Moreover, positive relationships with parents, family acceptance and family protection from homophobia (combined as family support), was found to buffer the negative effects of victimization on symptoms of psychological distress, but only when victimization was low and family support was high (Hershberger \& D'Augelli, 1995). Other positive parental relational dimensions, such as family connectedness, attachment, support, and parent-child relationship satisfaction have been explored and found to be associated with the mental health and well-being of GLB youths. For a review of parental influences in GLB development see Bouris et al. (2010). In this regard, more family connectedness and positive attachment were related to lower levels of psychological distress and suicidal ideation and attempts (Eisenberg \& Resnick, 2006; Ueno, 2005). Furthermore, satisfaction with parents was related to higher levels of self-esteem (Savin-Williams, 1989, as cited in Savin-Williams, 2003), and parental support was found to buffer the negative impact of 
homophobic bullying in suicidal ideation (António et al., 2012; Espelage et al., 2008; Needham \& Austin, 2010). For a review of the protective factors in GLB development see Saewyc (2011).

The literature on resilience also points to the fact that a person's positive outlook on life and similar views within the family are recognized as protective mechanisms in the face of adversity (Coimbra, 2008; Kwon, 2013; Masten \& Reed, 2002; Walsh, 2003). Optimism is related to mental health but also to the adoption of more long-term adaptive coping strategies, such as problem focused action/planning, or, when this is not possible, acceptance and positive reframing (Carver \& Scheier, 2002). Experimental studies suggest that persons with a pessimistic outlook on life regard the experience of prejudice as more threatening and consider having fewer assets to cope with the situation. This cognitive appraisal was, in turn, associated with diminished emotional well-being (Kaiser, Major, \& McCoy, 2004). Among a sample of GLB adults, optimism was found to be negatively associated with depression and positively associated with self-esteem (Morrison, 2011). Individual optimism and hope has proven to have a long-term positive impact on life satisfaction (Kwon \& Hugelshofer, 2010). Therefore, one would expect that a positive outlook on life, both at an individual and a family level, would be associated with higher levels of mental health.

The main goal of this study is to characterize, in a sample of Portuguese GLB youths (high school students), the associations between perceived discrimination and mental health, on the one hand, and familial optimism and family relationships (specifically, satisfaction, intimacy, admiration, and conflict with parents) on the other. Additionally, we explore whether family relational dimensions and optimism may function as protective mechanisms against high levels of perceived discrimination. Most of the aforementioned findings were observed within North American samples. However, cultural differences in terms of the social environment toward 
sexual minorities may exist between the USA and Portugal, where the present study was conducted. Portugal is a country with a Catholic heritage where family intergenerational ties are highly valued (Oliveira, Mendonça, Coimbra, \& Fontaine, 2014). Confronted with weak welfare policies, economic crisis and high levels of youth unemployment, the Portuguese youths depend greatly on family support, and tend to leave the parental home relatively late (Oliveira et al., 2014). The prospect of a delayed acquisition of autonomy can add more strain to parent-child relationships among Portuguese GLB youths. With regard to legislation, unequal treatment based on sexual orientation is deemed illegal by the Portuguese Constitution since 2004. However, only in 2010 the ban on same-sex marriage was removed (Almeida, 2010), while child adoption and assisted medical reproduction techniques are still not allowed for same-sex couples (Gato, Freitas, \& Fontaine, 2013). In Portugal, the most frequent manifestation of prejudice is heterosexism, i.e. an ideology that does not openly reject homosexuality, but that considers heterosexuality as superior (Gato, Fontaine, \& Carneiro, 2012; Gato \& Fontaine, 2013). It is also worth noting that none of the schools where data were collected for the present study had a student organization concerned with the well-being of GLBT youths. Social structures of this sort, such as the Gay-Straight Alliances found in the USA, are associated with higher levels of mental health and less victimization among GLB students (Saewyc, 2011). On a more proximal level, a qualitative study showed that Portuguese teachers manifest prejudiced attitudes toward sexual minorities, for instance, by perceiving gays and lesbians as individuals who have the reverse gender roles (Rodrigues, Brás, Cunha, Petiz, \& Nogueira, 2015). Aditionally, teachers manifested that school contexts are prevalently homophobic, and recognized the need of training on sexual diversity (Rodrigues, et al., 2015). Portuguese teachers' involvement seems to be mainly characterized by neglect and inaction. This non-affirming environment of GLB identities 
may increase experiences of discrimination among adolescents. In what concerns the association between mental health, discrimination, and family relational qualities, the aforementioned studies have revealed similar results, therefore suggesting a cross-cultural pattern of associations among these dimensions of analysis; hence, we have no reason to believe that they show a different pattern in our sample. In short, we expect the perception of discrimination to be associated with lower levels of mental health, and that a decrease in the youngsters' well-being may be buffered by positive parental relationships.

\section{Method}

\section{Participants}

Data were drawn from a larger study focusing on resilience of adolescents in the face of victimization. The larger study used a sample of 2975 students attending 24 high schools in Portugal's largest cities of Lisbon and Porto. Sexual orientation was evaluated in a closed-ended question, with options being heterosexual, bisexual, and gay/lesbian. These labels were matched with a brief note presenting sexual orientation as affection for and attraction to persons of different sex, persons of both sexes, and of same-sex, respectively. Information regarding disclosure (or concealment) of sexual orientation to parents and other significant persons was not collected. Some authors suggest that in order to evaluate sexual orientation researchers should assess multiple components (such as fantasies, attraction or behavior; see Russell, Clarke, \& Clary, 2009; Savin-Williams \& Ream, 2007). However, given the aims of the wider research, we considered that a single question regarding sexual orientation would be appropriate for the study's purposes.

Of the total sample, $97.1 \%(n=2975)$ identified as heterosexual; $2.4 \%(n=70)$ as bisexual; and $0.5 \%(n=14)$ as gay/lesbian. Responses from the 84 self-identified GLB youths 
were used in the study. Seven participants were gay males, seven were lesbians, 15 were bisexual males, and 55 were bisexual females. This pattern of self-definition of sexual orientation is consistent with the results of a study using a large representative sample of Portuguese adults, in which bisexual identities were more frequent than gay/lesbian, $1.5 \%$ vs. $0.7 \%$, respectively (Aboim, 2010). The higher frequency of self-defined bisexual individuals may be related to the sampling procedure of each study. For instance, studies conducted in the same geographical area (e.g. Northeastern United States) that used large probability samples have observed a higher percentage of bisexual when compared to gay/lesbian self-definitions (e.g. Bontempo \& D’Augelli, 2002; Savin-Williams \& Ream, 2007), while in studies using convenience samples, obtained mostly through GLB communities, have shown the opposite pattern (e.g. Kosciw, Palmer, \& Kull, 2015; Savin-Williams \& Diamond, 2000). In addition, the tendency for more females to self-indentify as bisexual, as compared to males, has also been observed in other contexts (cf. Savin-Williams \& Ream, 2007).

Overall, $73.8 \%$ of the sample were female $(n=62)$. Participants were between 14 and 21 years of age, being the mean age 16.77 years old $(S D=1.29)$. Around one third of the participants $(n=28)$ had parents with academic qualifications only up to the compulsory level, $35.4 \%(n=29)$ had at least one parent who completed secondary education (12 years of formal education), and 30.5\% $(n=25)$ had at least one parent with a college degree. Regarding race and ethnicity, most of the participants self-identified as White/Caucasian $(91.6 \% ; n=76)$, five $(6 \%)$ identified as Black, and two (2.4\%) identified as Mixed/Dark-skinned/Brown. Only seven (8.3\%) were not born in Portugal. Forty-six participants (78\%) declared they were Catholic or raised as Catholic, 11 (18.6\%) were atheist or agnostic, and two (3.4\%) had other Christian-based religion.

\section{Procedure}


After receiving approval from the Ethics Committee of the Faculty of Psychology and Education Sciences of the University of Porto, the National Data Protection Commission, and the Ministry of Education, public schools in the regions of Lisbon and Oporto were randomly selected. The directors of 24 schools (63.4\% of those contacted) allowed data collection between February 2013 and February 2014. Parents were informed of the study's main goal, procedure and data confidentiality. Informed consent was obtained from parents; students also provided verbal consent. The participation rate was $94.7 \%$. Students were informed about the study's main goal - to understand how youngsters deal with socially negative experiences - and the anonymity of their participation. Confidentially was granted to students who chose to leave contact information (e.g., e-mail) for additional participation in the research project. Data were collectively gathered by the first author.

\section{Measures}

\section{Mental Health}

For the evaluation of the participants' mental health, we used the Portuguese adaptation of the Mental Health Inventory-5 items (Ribeiro, 2001; Veit \& Ware, 1983), which evaluates symptoms of distress and psychological well-being. As the scale authors suggest (Veit \& Ware, 1983), the conceptualization of mental health used in this study corresponds to the absence of mental distress and the perception of well-being. This concept thus matches the World Health Organization (WHO, 2014) current definition of health, as a "state of complete physical, mental and social well-being and not merely the absence of disease or infirmity" (para. 2). The 5 items ("How much of the time during the last month have you: been very nervous; felt calm and peaceful; sad and down; happy; and sad and down that nothing could cheer you up?") were rated on a 5-point Likert type scale from 1 (never) to 5 (almost always), and the scale revealed a high 
internal reliability (Cronbach's $\alpha=.85$ ). Higher scores signified mental health and absence of psychological distress.

\section{Discrimination}

Perceived discrimination was assessed through an adaptation of the Everyday Discrimination Scale (Freitas, Coimbra, Marturano \& Fontaine, in press; Williams, Yu, Jackson, \& Anderson, 1997). The scale measures the frequency of "minor experiences of unfair treatment" (Williams et al., 1997, p. 340) that can happen routinely in one's daily life. Although the scale was originally conceived to be unidimensional, the adaptation revealed two factors with four items each (seven items were from the original scale and one was developed for the purposes of the present study in order to specifically address GLB discrimination; Freitas, Coimbra, Marturano \& Fontaine, in press). The two factors were named Unfair Treatment (e.g., being called names or insulted/threatened or harassed) and Personal Rejection (e.g., people act as if they are better than you/something is wrong with you). Items were rated in a 6-point Likert type scale ranging from 0 (never) to 5 (almost always/almost every day) and the subscales revealed good internal reliability (Unfair Treatment Cronbach's $\alpha=.84$; Personal Rejection Cronbach's $\alpha=.76)$.

\section{Family Environment Dimensions}

To assess positive beliefs within the family system we used a revised version of the Portuguese adaptation of the Life Orientation Test-Revised (Laranjeira, 2008; Scheier \& Carver, 1985). Items were modified so as to focus on the assessment on the family as a whole; for example, "Overall, in my family we expect more good than bad things to happen/we are always optimistic about the future". Five items of the scale were used, and participants rated them in a 5- 
point Likert type scale ranging from 1 (totally disagree) to 5 (totally agree). The scale showed good internal reliability (Cronbach's $\alpha=.73$ ).

To assess the qualities of the relationship with the mother and the father we used the Portuguese adaptation of the Network of Relationships Inventory (Furman \& Buhrmester, 1985, 1992). Four subscales of the instrument were selected: Satisfaction (e.g., I'm happy/satisfied with the way things are between me and him/her), Intimacy (e.g., talk to him/her about things; share secrets/feelings), Admiration (e.g., likes or approves of the things I do/treats me with admiration and respect) and Conflict (e.g. we disagree/get angry). Participants were asked to rate each of the 12 items (four of each subscale) relative to their mothers and their fathers, separately. In the absence of these parental figures, other adult caregivers could be chosen. Ninety-one percent of the participants chose their biological mother, $82 \%$ chose the biological father, and the other most mentioned caregivers were stepmothers, stepfathers, and grandparents. Responses were given in a 5-point Likert type scale ranging from 1 (never/rarely) to 5 (always) and all subscales showed good internal reliability (Cronbach's $\alpha=.74$ to .92 ).

\section{Results}

The mean value observed in the levels of mental health $(M=3.01 ; S D=0.92)$ indicates that participants generally felt mentally healthy only some of the time. To explore the association of mental health with discrimination and family environment dimensions, contrasting groups were created according to the reported level of mental health. This procedure has taken into account the middle point of the mental health Likert type scale (that was 3), the mode, median, and mean values (that were also 3), and the distribution of result scores. Participants whose results were below the value $2.6(n=32 ; 38.1 \%)$ were categorized as Low Mental Health $(\mathrm{MH})$; those whose values were above 3.4 were categorized as High Mental Health $(n=33 ; 39.3 \%)$. 
The mean level of mental health in the Low MH group $(M=2.08 ; S D=0.44)$ was significantly lower when compared with the High MH group $(M=3.96 ; S D=0.44 ; F(1,64)=295.13, p<$ $.001, \eta^{2}=.82$ ). Results show that these two groups are also statistically contrasting; participants in the Low MH group are almost never psychologically well, while those in the High MH group are mentally healthy most of the time.

\section{Discrimination and Family Environment in Low and High Mental Health Groups}

The aforementioned two groups were then compared in terms of their experiences of discrimination and family variables. The results of the multiple analyses of variance are presented in Table 1. Significant differences were found between the Low and High MH groups regarding perceived discrimination (unfair treatment and personal rejection), familial optimism, fathers' admiration, and conflict with both parents. As expected, the group of High MH reported very infrequent discrimination: most participants said it occurred rarely or less than once a year. On the other hand, Low MH reported experiencing discrimination behaviors more than once a year to several times a year.

\section{[INSERT TABLE 1 ABOUT HERE]}

Regarding the level of familial optimism, High MH adolescents perceived their families to be significantly more optimistic than Low $\mathrm{MH}$ adolescents. As regards family relationships, participants were often satisfied with their relationship with both parents, and there were no differences between the Low MH and High MH groups. The results in the subscale of intimacy suggest that the participants did not talk frequently about personal matters with their parents, and no differences were found between Low MH and High MH groups about this point. In terms of parental admiration and respect, significant differences only emerged regarding fathers; while High MH participants felt more often appreciated by fathers, Low MH participants only felt 
valued by fathers some of the time. No differences emerged regarding the admiration felt by mothers, and mean values indicate that participants felt appreciated by their mothers frequently. Significant differences were also observed in the levels of conflict; while Low MH reported having conflicts with parents frequently, High MH reported only occasionally having conflicts with parents.

\section{Family Environment as Moderator of the Relationship between Discrimination and Mental Health}

Relationships between mental health, discrimination, and family environment dimensions are congruent with the associations already identified in the comparison of Low and High $\mathrm{MH}$ groups. Table 2 shows the correlations, using Pearson's product-moment bivariate correlations. Negative and moderate correlations were observed between mental health levels and discrimination. Familial optimism showed a moderate positive correlation with mental health. Admiration expressed by fathers evidenced a modest positive correlation with mental health. The other positive qualities of the relationships with parents showed no significant associations with mental health. Finally, conflicts with both parents were negatively and moderately correlated with mental health. Taking into account the effect sizes of the differences found among the Low and High MH groups, and the intensity of the correlations with the indicator of mental health, we conclude that the two dimensions of the Everyday Discrimination Scale - Unfair Treatment and Personal Rejection - are more strongly associated with the mental health of the GLB adolescents than the family dimensions. Additionally, family qualities were significant and moderately associated with each other. When the relationships with parents were more satisfactory, there was more personal sharing of information (intimacy), more expression of approval and respect by the parent, and less conflict. The participants' rating of the relationships with mothers and 
fathers on the same dimensions are significantly correlated, except for relationship satisfaction, thus revealing that higher intimacy, admiration, and less conflict with mothers are associated with higher intimacy, admiration, and less conflict with fathers. Still, given the small magnitude of these correlations, we conclude that adolescents perceived their relationships with each parent differently (see Table 2). Overall, results suggest that in GLB adolescents' family relationships there is a general climate which can be described as more or less positive.

\section{[INSERT TABLE 2 ABOUT HERE]}

Considering the significant differences found between Low and High MH and the pattern of relationships among mental health, discrimination, and family environment dimensions, we sought to determine whether familial optimism, admiration shown by fathers, and conflict with parents, moderated the relationship between perception of discrimination and mental health. Considering the sample size and in order to simplify the results, we combined the two scales of perception of discrimination into a single indicator (subscales were significantly and positively correlated, see Table 2). Similarly, as the conflict with the mother and the father were significantly and positively correlated (see Table 2), we combined the two subscales into a single indicator. Regression analyses were carried out in AMOS software (v. 22, SPSS Inc., Chicago, IL) with all variables means centered $(M=0)$.

The moderation model regarding familial optimism shows that a positive outlook within the family is not a significant moderator in the relation between discrimination and mental health $\left(\beta_{\text {discrimination }}=-.42 ; B=-.40, Z=-4.29, p<.001 ; \beta_{\text {optimism }}=.22, B=.29, Z=2.25, p=.025 ;\right.$ $\left.\beta_{\text {discrimination }{ }^{*} \text { optimism }}=-.02, B=-.02, Z=-0.18, p=.860\right)$. Regarding the admiration expressed by fathers, the moderation model showed that this family dimension is not a moderator in the relation between discrimination and mental health $\left(\beta_{\text {discrimination }}=-.58, B=-.55, Z=-5.12, p<\right.$. 
$001 ; \beta_{\text {father's admiration }}=.22, B=.19, Z=2.35, p=.019 ; \beta_{\text {discrimination } * \text { father's admiration }}=.20, B=.15, Z$

$=1.81, p=.071)$. In contrast, conflict with both parents was a significant moderator in the relationship between the perception of discrimination and mental health $\left(\beta_{\text {discrimination }}=-.42, B=\right.$ $.40, Z=-4.518, p<.001 ; \beta_{\text {conflict }}=-.26, B=-.30, Z=-2.77, p=.006 ; \beta_{\text {discrimination }{ }^{*} \text { conflict }}=.22, B=$ $.27, Z=2.44, p=.015)$. Thus, the effects of the perception of discrimination are associated with the effects of conflict with parents. The interactive effects of the perception of discrimination and conflict with parents in mental health were estimated to explain $33 \%$ of the variance in mental health $\left(R^{2}=.33\right)$. Following the suggestions of Jose $(2013 \mathrm{a})$, graphing moderation patterns were computed using the Excel-based version of ModGraph (Jose, 2013b). Figure 1 illustrates the graph with the predicted values for mental health regarding the interaction between perception of discrimination and conflict with parents.

\section{[INSERT FIGURE 1 ABOUT HERE]}

Significant differences were found between the predicted values when conflict with parents was low $(t(80)=-4.63, p<.001)$ and medium $(t(80)=-3.35, p=.001)$, but not when the conflict was high $(t(80)=-1.55, p=.125)$. For low and medium levels of conflict with parents, the effect of discrimination is not as pronounced as when conflict with parents is high. When conflict with parents is high, mental health is estimated to be affected regardless of the levels of discrimination experienced. Overall, results suggest that discrimination has a higher impact on mental health than conflict with parents. When discrimination values are high, the absence of conflicts with parents is not protective of the negative effects of the victimization in mental health, contrary to what happens when discrimination values are low or medium. Additionally, when either conflicts with parents, or the perception of discrimination, are frequent GLB adolescents' mental health is jeopardized. 


\section{Discussion}

In this study we sought to explore the associations between mental health, discrimination, and family environment variables, relationships with both parents and optimism, in a nonconvenience sample of Portuguese GLB youths. Results show that around $16 \%$ of the variance in mental health is associated with the perception of discrimination. Moreover, adolescents with low levels of mental health report experiencing acts of discrimination frequently. These results are consistent with the literature which reveals that victimization of GLB youths has a negative impact on mental health (e.g., D’Augelli, 2002; Fedewa \& Ahn, 2011), and that a considerable number of GLB youths are frequent victims of prejudice.

A positive relationship was found between familial optimism and mental health. Our results suggest that sharing a positive outlook within the family has a direct impact on mental health. The positive association with mental health is consistent with the literature which shows that optimism, at the individual and the family level, is an important resource in front of adverse events, and is related to higher levels of well-being (Kwon, 2013; Kwon \& Hugelshofer, 2010; Masten \& Reed, 2002; Morrison, 2011, Walsh, 2003). In parallel with individual optimism (Carver \& Scheier, 2002), a generally positive family outlook on life may also foster trust in the future among its members (mothers, fathers, and GLB youths), and the ability to better cope with stress. For instance, GLB youths whose family shares a positive outlook on life may be more hopeful about the future, show higher levels of acceptance of diverse sexual orientations, and be more resolute when facing stressful situations. On the other hand, among families where pessimism runs high, there may be a tendency for people to anticipate negative events and to use less adaptive coping strategies, such as avoidance, when facing challenging situations. In the case of the development of a non-heterosexual identity, this could mean that adolescents, and/or 
their parents, may regard their sexual/emotional attractions as "a phase" that is best ignored. Such an appraisal can be associated with a delay in the consolidation of a positive image of their sexual orientation. Concomitantly, GLB youths with pessimistic family members may possibly be more secretive about their sexuality for fear that their parents will regard it as "a problem" and may be reluctant to impose on them a new burden associated with the challenge of accepting and supporting their son's/daughter's non-heterosexuality. Despite its limited buffering effect on discrimination, belonging to an optimistic family seems to be a valuable resource for children and families. This result provides additional support for social actions aiming to increase levels of optimism and hope among GLB youth, and their families, such as the It Gets Better Project (2010).

With regard to parental relationships, we observed that mental health was not significantly associated with satisfaction and closeness with both parents, and with mother's admiration. These results are surprising given the previous observations pointing to family connectedness and attachment with parents being related to less emotional distress (Eisenberg \& Resnick, 2006; Floyd et al., 1999; Hershberger \& D'Augelli, 1995; Resnick et al., 1997; Ueno, 2005). A possible explanation for the non-confirmation of our hypothesis that the positive qualities of relationships with parents would be positively associated with the youngsters' mental health may be related with the instruments used to assess mental health. General positive family interactions (not those specifically associated with sexual orientation, e.g., family acceptation) may show a significant association with certain psychological disorders, but not with positive affect (e.g., the Mental Health Inventory, which asks participants about frequency of positive feelings). Another possible explanation is that these general positive family dimensions may only have an indirect association with mental health. This possible indirect association may be 
mediated by specific dimensions of the homo/bisexual identity development, such as the levels of fear associated with a negative parental reaction regarding homosexuality, minority stress, internalized homonegativity, or sensitivity to rejection (Feinstein et al., 2012; Meyer, 2003; Morrison, 2011; Savin-Williams, 2003). These hypotheses should be explored in future studies. The only observed exception to this pattern concerns the perception of admiration by the father. This dimension was significantly associated with less distress in the GLB adolescents in our study. Furthermore, participants with higher levels of mental health felt more valued by their male parental figures. The literature shows that fathers are seen as figures of social validation, authority, and instrumental support, while mothers are more associated with emotional care and support (e.g., Smetana et al., 2006). The impact of the approval and respect expressed by fathers may have a more intense association with mental health due to the gender role associations attached this parental figure. For GLB youths, knowing that the main figure of authority in their lives, the gatekeeper of society's moral standards, expresses approval and respect toward their individuality seems to have a greater impact on their mental health than the approval expressed by the mother, which is more commonly assured. Moreover, considering that feelings of sexual prejudice and homophobia are more prevalent among males (Gato et al., 2012; Herek, 2000), and that fathers usually express more negative attitudes in front of "deviations" from heterosexuality and normative gender expression than mothers (D'Augelli et al., 2006, 1998), higher levels of admiration felt by fathers may have a special meaning, and be more valued, by the GLB adolescents. Another possible explanation is related to the fact that our sample is mostly composed of females, and research suggests relationships between daughters and fathers face more challenges and involve higher levels of detachment, during adolescence (Youniss \& Smollar, 1985, as cited in Lempers \& Clark-Lempers, 1992; Shanahan et al., 2007). Such typical 
detachment may have contributed to a greater prominence in the levels of perceived admiration by the fathers in our sample. The surprisingly great expressions of appreciation by the father were, in turn, associated with the levels in mental health. Feelings of admiration by the father did not interacted with the perceptions of discrimination on mental health, but were, nevertheless, associated to higher levels of mental health. Thus, this relational quality is a valuable asset for GLB youths, whether or not they have experienced discrimination.

We observed that conflict, the only negative feature of parent-child relationships assessed, was significantly related to lower levels of mental health. This result is consistent with previous findings (e.g., Ueno, 2005). Our results also indicate that a high level of family conflict entails an additional risk for adolescents who experience discrimination, intensifying the negative impact of low to moderate levels of the latter. A similar result was also found in a study with ethnic monitories: Juang and Alvarez (2010) found that having frequent conflicts with parents exacerbated the negative influence of discrimination on loneliness and anxiety. The moderation effect of conflict with parents in the relation between perceptions of discrimination and mental health suggests that family conflict can be conceptualized as vulnerability mechanism (Luthar et al., 2000). In this case, the absence of conflicts does not totally remove the negative impact of discrimination, but the having conflictual family relationships with parents increases the negative impact of discrimination, when its acts are not frequent. Despite the absence of information regarding the main motives for conflict with parents, we do not exclude the possibility that the non-heterosexuality of the participants is related to increasing conflict with parents in the group displaying low levels of mental health (D'Augelli, 2005; Ryan et al., 2009). Studies suggest that GLB youths have higher rates of conflicts with parents, compared to their heterosexual counterparts (Ueno, 2005). In addition, results also suggest that when the 
perception of discrimination is high, the absence of family conflict is not sufficient to buffer its negative impact. This result poses a new challenge for schools and professionals that work with adolescents. Although conflict with parents could be regarded as a common family occurrence, it is important for professionals who work with adolescents, such as teachers, to understand that these conflicting situations consist of added challenges for those who are already being victimized in other contexts. The interactive and cumulative effect of conflict and victimization in different contexts puts GLB youths at a considerably greater risk of mental health problems. Additionally, our results suggest a general pattern of family relationships of GLB youths. Higher conflicts with parents are related to less parental appreciation, less personal and emotional disclosure by the adolescent and less relationship satisfaction. In our study, adolescents who manifested low levels of mental health had more pessimistic families, felt less appreciated by their fathers, and exhibited more conflicts with both parents. A negative and less supportive family environment is associated with worse mental health among GLB youths, even when they are not victims of discrimination, and have positive peer relationships. Moreover, the buffering effect of low conflict levels with parents is neutralized nullified when acts of discrimination are frequent. Again, this poses an additional challenge for professionals since they cannot rely on adolescents' positive relationships to buffer the negative impact of discrimination. Given that the pervasive impact of discrimination on mental health is not easily weakened by other positive life circumstances, professionals who work with adolescents must make efforts to foster the decrease of environmental levels of homophobic prejudice.

Taking these results as a whole, one can conclude that the effect of the negative relational aspects - perception of discrimination and conflict with parents - is stronger than the positive familial qualities - father's admiration and familial optimism - when it comes to their impact on 
mental health. Baumeister, Bratslavsky, Finkenauer, and Vohs (2001)'s review of the impact of negative and positive events in several life domains, such as close relationships, self, health, and happiness, suggests that negative events have a stronger impact than positive events. A similar effect was also found in GLB youths' mental health, where negative parental control exerted a stronger influence in the symptoms of psychological disorders than parental acceptance (Bebes et al., 2015). Our results corroborate these findings for Portuguese GLB adolescents. Most of the positive dimensions assessed had small or no significant associations with their mental health, in contrast with the observed impact of negative interactions.

Our results suggest that in order to foster the mental health of GLB youths, it is indispensable to decrease the number of stressors, such as discrimination and conflict with parents. Still, as observed in other studies (e.g., Robinson \& Espelage, 2012), discrimination and family environment dimensions are assumed to explain only partially the variations in mental health. Other factors within the individual, the family, and the social context have important effects on GLB adolescents' mental health. Studies have shown that it is possible (and desirable) for schools to promote a positive development of sexual minorities, namely, by the inclusion of sexual orientation related matters in curricula, the development of policies aimed specifically at decreasing homophobic violence, the training of school staff to deal with discriminatory situations, and the encouragement of student associations to focus on the well-being of GBL youths (Saewyc, 2011). Additionally, other societal factors are related to high mental health levels and well-being of GLB individuals and their families, namely, the implementation of nondiscriminative legislation, such as the establishment of equal rights within marriage and family planning (Bos, Gartrell, Peyser, \& van Balen, 2008; Bos, Gartrell, van Balen, Peyser, \& Sandfort, 2008; Goldberg \& Kuvalanka, 2012). Parents and persons who work directly with 
adolescents (such as teachers) must manifest their support in favor of non-discrimination and work to change the prevalent heterosexist social environment.

\section{Limitations and implications for future research}

One limitation of the present study derives from its cross-sectional nature which may limit any inferences of causality. Still, the literature on victimization suggests that discrimination causes distress and not the other way around (Brody et al., 2006). However, in the case of conflicting relationships with parents and their impact on mental health, it is difficult to tell whether adolescents in distress are more prone to conflict with parents, as well as with other significant figures, such as friends. Relationships are reciprocal and thus more suited for systemic analyses instead of causal inferences. In order to make clearer the directions of effects in parent-child relationships, future studies should focus on family relationships, preferably using a longitudinal methodology as well as the collection of dyadic data (parents and GLB adolescents). Another significant limitation of the study concerns the absence of information about disclosure, or concealment, of sexual orientation. Studies show that relationships with parents, as previously mentioned, are susceptible to increased stress in the face of adolescents' disclosure of non-heterosexuality (D’Augelli et al., 2008). Thus, research regarding sexual orientation ought to include this kind of sensitive information concerning coming out. Additionally, due to the sample size, it was not possible to explore gender effects in the observed relationships between discrimination, family environment dimensions and mental health. Future research should focus in the interaction between the gender of the child and the gender of the parent as a possible moderator of the pattern of associations that can be observed.

\section{Concluding remarks}


Drawing on a non-convenience sample, our results corroborate some of the results found in previous studies; mainly, the detrimental and stronger impact of negative interactions on the mental health of sexual minorities. Perception of discrimination was the dimension mostly associated with lower levels of mental health. This negative impact of discrimination does not interact with positive qualities in family relationships related to mental health, such as optimism and father's admiration. This result suggests that feelings of respect and appreciation from fathers with regard to the singularity of their children, and a positive outlook toward the future within the family, constitute family assets associated with the well-being of GLB youths, regardless of the levels of discrimination they may experience. Additionally, having no conflicting relationships with parents is a significant protective mechanism of GLBs' mental health in the face of occasional acts of discrimination. Additionally, even when discrimination is rare and GLB youths experience positive relationships at school, it is important for professionals to take into account aspects concerning their family environment. GLB youths who experience frequent conflicts with their parents are at a higher risk of developing mental health problems, even in the absence of discrimination. Thus, in order to promote the well-being of GLB youths, it is crucial for professionals to focus on the promotion of positive family relationships as well as on bringing down the levels of homophobia present in the social environment. 


\section{References}

Aboim, S. (2010). Homossexualidade e bissexualidade: Práticas, atracção e orientação sexual [Homosexuality and bisexuality: Practices, attraction and sexual orientation]. In. P. M. Ferreira \& M. V. Cabral (Eds.) Sexualidades em Portugal, Comportamentos e Riscos (pp.147-200). Lisboa: Bizâncio

Almeida, M. V. (2010). O contexto LGBT em Portugal [The LGBT Portuguese context]. In C. Nogueira \& J. M. Oliveira (Eds.), Estudo sobe a discriminação em função da orientação sexual e da identidade de género [Study regarding discrimination in function os sexual orientation and gender identity] (pp. 45-92). Lisboa: Comissão para a Cidadania e a Igualdade de Género.

António, A. R., Pinto, T., Pereira, C., Farcas, D. \& Moleiro, C. (2012). Bullying Homofóbico no contexto escolar em Portugal [Homophobic bullying in the Portuguese school context]. Psicologia, 26(1) 17-32.

Baumeister, R. F., Bratslavsky, E., Finkenauer, C., \& Vohs, K. D. (2001). Bad is stronger than good. Review of General Psychology, 5(4), 323-370. doi:10.1037/1089-2680.5.4.323

Beasley, C. R., Jenkins, R. A., \& Valenti, M. (2015). Special section on LGBT resilience across cultures: Introduction. American Journal of Community Psychology, 55, 164-166. doi:10.1007/s10464-015-9701-7

Bebes, A., Samarova, V., Shilo, G., \& Diamond, G. M. (2015). Parental acceptance, parental psychological control and psychological symptoms among sexual minority adolescents. Journal of Child and Family Studies, 24, 882-890. doi:10.1007/s10826-013-9897-9 
Bontempo, D. E., \& D’Augelli, A. R. (2002). Effects of at-school victimization and sexual orientation on lesbian, gay, or bisexual youths' health risk behavior. Journal of Adolescent Health, 30(5), 364-74. doi:10.1016/S1054-139X(01)00415-3

Bos, H., Gartrell, N., Peyser, H., \& van Balen, F. (2008). The USA National Longitudinal Lesbian Family Study (NLLFS): Homophobia, psychological adjustment, and protective factors. Journal of Lesbian Studies, 12(4), 455-71. doi:10.1080/10894160802278630

Bos, H., Gartrell, N., van Balen, F., Peyser, H., \& Sandfort, T. G. M. (2008). Children in planned lesbian families: A cross-cultural comparison between the United States and the Netherlands. American Journal of Orthopsychiatry, 78(2), 211-219. doi:10.1037/a0012711

Bouris, A., Guilamo-Ramos, V., Pickard, A., Shiu, C., Loosier, P. S., Dittus, P., Gloppen, K. \& Waldmiller, J. (2010). A systematic review of parental influences on the health and wellbeing of lesbian, gay, and bisexual youth: Time for a new public health research and practice agenda. Journal of Primary Prevention, 31, 273-309. doi:10.1007/s10935-0100229-1

Brody, G. H., Chen, Y., Murry, V. M., Ge, X., Simons, R. L., Gibbons, F. X., Gerrard, M. \& Cutrona, C. E. (2006). Perceived discrimination and the adjustment of African American youths: a five-year longitudinal analysis with contextual moderation effects. Child Development, 77(5), 1170-89. doi:10.1111/j.1467-8624.2006.00927.x

Carver, C. S., \& Scheier, M. F. (2002). Optimism. In C.R. Snyder \& S. J. Lopez (Eds.), The handbook of positive psychology (pp. 231-243). New York: Oxford University Press.

Chae, D. H., Krieger, N., Bennett, G. G., Lindsey, J. C., Stoddard, A. M., \& Barbeau, E. M. (2010). Implications of discrimination based on sexuality, gender, and race/ethnicity for psychological distress among working-class sexual minorities: The United for Health Study, 
2003-2004. International Journal of Health Services, 40(4), 589-608.

doi:10.2190/HS.40.4.b

Coimbra, S. (2008). Estudo diferencial de auto-eficácia e resiliência na antecipação da vida adulta [Differential study of self-efficacy and resilience in anticipation of adulthood]. Unpublished master's thesis, Faculdade de Psicologia e de Ciências da Educação da Universidade do Porto, Porto.

D’Augelli, A. R. (1998). Developmental implications of victimization of lesbian, gay and bisexual youths. In G.M. Herek (Ed.) Stigma and sexual orientation: Understanding prejudice against lesbians, gay men and bisexuals (pp.187-210). Sage: Thousand Oaks.

D’Augelli, A. R. (2002). Mental health problems among lesbian, gay, and bisexual youths ages 14 to 21. Clinical Child Psychology and Psychiatry, 7(3), 433-456. doi: $10.1177 / 1359104502007003039$

D’Augelli, A. R. (2005). Stress and adaptation among families of lesbian, gay, and bisexual youth. Journal of GLBT Family Studies, 1(2), 37-41. doi:10.1300/J461v01n02_07

D’Augelli, A. R., Grossman, A. H., \& Starks, M. T. (2006). Childhood gender atypicality, victimization, and PTSD among lesbian, gay, and bisexual youth. Journal of Interpersonal Violence, 21(11), 1-21. doi:10.1177/0886260506293482

D’Augelli, A. R., Grossman, A. H., \& Starks, M. T. (2008a). Families of gay, lesbian, and bisexual youth. Journal of GLBT Family Studies, 4(1), 95-115. doi:10.1080/15504280802084506

D’Augelli, A. R., Grossman, A. H., \& Starks, M. T. (2008b). Gender atypicality and sexual orientation development among lesbian, gay, and bisexual youth. Journal of Gay \& Lesbian Mental Health, 12(1-2), 121-143. doi:10.1300/J529v12n01_08 
D’Augelli, A. R., Hershberger, S. L., \& Pilkington, N. W. (1998). Lesbian, gay, and bisexual youth and their families: Disclosure of sexual orientation and its consequences. American Journal of Orthopsychiatry, 68(3), 361-371. doi:10.1037/h0080345

Eisenberg, M., \& Resnick, M. (2006). Suicidality among gay, lesbian and bisexual youth: the role of protective factors. Journal of Adolescent Health, 39(5), 662-668. doi:10.1016/j.jadohealth.2006.04.024

Elamé, E. (2013). Discriminatory bullying: A new intercultural challenge. Italia: SpringerVerlag. doi:10.1007/978-88-470-5235-2

Espelage, D. L., Aragon, S. R., Birkett, M., \& Koenig, B. W. (2008). Homophobic teasing, psychological outcomes, and sexual orientation among high school students: What influence do parents and schools have? School Psychology Review, 37(2), 202-216.

Fedewa, A. L., \& Ahn, S. (2011). The effects of bullying and peer victimization on sexualminority and heterosexual youths: A quantitative meta-analysis of the literature. Journal of GLBT Family Studies, 7(4), 398-418. doi:10.1080/1550428X.2011.592968

Feinstein, B. A., Goldfried, M. R., \& Davila, J. (2012). The relationship between experiences of discrimination and mental health among lesbians and gay men: An examination of internalized homonegativity and rejection sensitivity as potential mechanisms. Journal of Consulting and Clinical Psychology, 80(5), 917-927. doi:10.1037/a0029425

Fergus, S., \& Zimmerman, M. A. (2005). Adolescent resilience: a framework for understanding healthy development in the face of risk. Annual Review of Public Health, 26, 399-419. doi:10.1146/annurev.publhealth.26.021304.144357 
Floyd, F. J., \& Stein, T. S. (2002). Sexual orientation identity formation among gay, lesbian, and bisexual youths: multiple patterns of milestone experiences. Journal of Research on Adolescence, 12(2), 167-191. doi:10.1111/1532-7795.00030

Floyd, F. J., Stein, T. S., Harter, K. S. M., Allison, A., \& Nye, C. L. (1999). Gay, lesbian, and bisexual youths: Separation-individuation, parental attitudes, identity consolidation, and well-being. Journal of Youth and Adolescence, 28(6), 719-739.

doi:10.1023/A:1021691601737

Freitas, D., Coimbra, S., Marturano, E. M., \& Fontaine, A. M. (in press). Escala de Discriminação Quotidiana: Adaptação do instrumento para jovens portugueses [Everyday Discrimination Scale: Adaptation of the instrument to the Portuguese youth]. Psicologia:Reflexão e Crítica

Furman, W., \& Buhrmester, D. (1985). Children's perceptions of the personal relationships in their social networks. Developmental Psychology, 21(6), 1016-1024. doi:10.1037//00121649.21.6.1016

Furman, W., \& Buhrmester, D. (1992). Age and sex differences in perceptions of networks of personal relationships. Child Development, 63, 103-115. doi:10.1111/j.14678624.1992.tb03599.x

Gato, J., \& Fontaine, A. M. (2013). Anticipation of the sexual and gender development of children adopted by same-sex couples. International Journal of Psychology, 48(3), 244253. doi:10.1080/00207594.2011.645484

Gato, J., Fontaine, A. M., \& Carneiro, N. S. (2012). Escala multidimensional de atitudes face a lésbicas e a gays: Construção e e validação preliminar [Multidimensional scale of attitudes 
toward lesbians and gay men: Construction and preliminary validation]. Paidéia, 22(51), $11-20$.

Gato, J., Freitas, D., \& Fontaine, A. M. (2013). Attitudes toward same-sex parenting: Exploratory, confirmatory, and invariance analyses of two psychometric scales. Journal of GLBT Family Studies, 9(3), 205-229. doi:10.1080/1550428X.2013.781906

Goldberg, A. E., \& Kuvalanka, K. A. (2012). Marriage (in)equality: The perspectives of adolescents and emerging adults with lesbian, gay, and bisexual parents. Journal of Marriage and Family, 74(1), 34-52. doi:10.1111/j.1741-3737.2011.00876.x

Herek, G. M. (2000). The psychology of sexual prejudice. Current Directions in Psychological Science. doi:10.1111/1467-8721.00051

Hershberger, S. L., \& D'Augelli, A. R. (1995). The impact of victimization on the mental health and suicidality of lesbian, gay, and bisexual youths. Developmental Psychology, 31(1), 6574. doi:10.1037/0012-1649.31.1.65

Jose, P. E. (2013a). Doing statistical mediation and moderation. New York: The Guilford Press

Jose, P. E. (2013b). ModGraph-I: A programme to compute cell means for the graphical display of moderational analyses: The internet version, Version 3.0. Victoria University of Wellington, Wellington, New Zealand. Retrieved in February 2015 from http://pavlov.psyc.vuw.ac.nz/paul-jose/modgraph/

Juang, L., \& Alvarez, A. (2010). Discrimination and adjustment among chinese american adolescents: Family conflict and family cohesion as vulnerability and protective factors. American Journal of Public Health, 100(12), 2403-2409. doi:10.2105/AJPH.2009.185959 
Kaiser, C. R., Major, B., \& McCoy, S. K. (2004). Expectations about the future and the emotional consequences of perceiving prejudice. Personality and Social Psychology Bulletin, 30(2), 173-84. doi:10.1177/0146167203259927

Katz-Wise, S. L., \& Hyde, J. S. (2012). Victimization experiences of lesbian, gay, and bisexual individuals: a meta-analysis. Journal of Sex Research, 49(2-3), 142-67. doi:10.1080/00224499.2011.637247

Kosciw, J. G., Palmer, N. A., \& Kull, R. M. (2015). Reflecting resiliency: Openness about sexual orientation and/or gender identity and its relationship to well-being and educational outcomes for LGBT students. American Journal of Community Psychology, 55, 167-178. doi:10.1007/s10464-014-9642-6

Kwon, P. (2013). Resilience in lesbian, gay, and bisexual individuals. Personality and Social Psychology Review, 17(4), 371-383. doi:10.1177/1088868313490248

Kwon, P., \& Hugelshofer, D. S. (2010). The protective role of hope for lesbian, gay, and bisexual individuals facing a hostile workplace climate. Journal of Gay \& Lesbian Mental Health, 14(1), 3-18. doi:10.1080/19359700903408914

Laranjeira, C. A. (2008). Tradução e validação portuguesa do revised life orientation test (LOTR). Universitas Psychologica, 7(2), 469-476.

LaSala, M. C. (2000). Lesbians, gay men, and their parents: Family therapy for the coming-out crisis. Family Process, 39(1), 67-81. doi:10.1111/j.1545-5300.2000.39108.x

Leme, V. B. R., Del Prette, Z. A. P., \& Coimbra, S. (2013). Práticas educativas parentais e habilidades sociais de adolescentes de diferentes configurações familiares [Parenting practices and social skills by adolescent of different family configurations]. Psico, 44(4), $560-570$. 
Lempers, J. D., \& Clark-Lempers, D. S. (1992). Young, middle, and late adolescents’

comparisons of the functional importance of five significant relationships. Journal of Youth and Adolescence, 21(1), 53-96. doi: 10.1007/BF01536983

Luthar, S. S., Cicchetti, D., \& Becker, B. (2000). The construct of resilience: a critical evaluation and guidelines for future work. Child Development, 71(3), 543-62. doi:10.1111/14678624.00164

Masten, A.S., \& Reed, M.G. (2002). Resilience in development. In C.R. Snyder \& S. J. Lopez (Eds.), The handbook of positive psychology (pp. 74-88). New York: Oxford University Press.

Mays, V. M., \& Cochran, S. D. (2001). Mental health correlates of perceived discrimination among lesbian, gay, and bisexual adults in the United States. American Journal of Public Health, 91(11), 1869-76. doi:10.2105/AJPH.91.11.1869

Meyer, I. H. (2003). Prejudice, social stress, and mental health in lesbian, gay, and bisexual populations: conceptual issues and research evidence. Psychological Bulletin, 129(5), 67497. doi:10.1037/0033-2909.129.5.674

Morrison, M. A. (2011). Psychological health correlates of perceived discrimination among Canadian gay men and lesbian women. Canadian Journal of Community Mental Health, 30(2), 81-98. doi:10.7870/cjemh-2011-0018

Murdock, T. B., \& Bolch, M. B. (2005). Risk and protective factors for poor school adjustment in lesbian, gay, and bisexual (LGB) high school youth: Variable and person-centered analyses. Psychology in the Schools, 42(2), 159-172. doi:10.1002/pits.20054 
Needham, B. L., \& Austin, E. L. (2010). Sexual orientation, parental support, and health during the transition to young adulthood. Journal of Youth and Adolescence, 39, 1189-1198. doi:10.1007/s10964-010-9533-6

Oliveira, C. A. N. (2012). Amor parental (in)condicional: Estudo sobre a influência da perceção da aceitação/rejeição parental em homossexuais, lésbicas e bissexuais [Parental (un)condicional love: Study about the influence the of perceptions of parental acceptance/rejection in gay, lesbian and bisexuals]. Unpublished master's thesis, Instituto Superior da Maia, Maia, Portugal.

Oliveira, J. E., Mendonça, M., Coimbra, S., \& Fontaine, A. M. (2014). Family support in the transition to adulthood in Portugal - Its effects on identity capital development, uncertainty management and psychological well-being. Journal of Adolescence, 37(8), 1449-1462. doi:10.1016/j.adolescence.2014.07.004

Resnick, M. D., Bearman, P. S., Blum, R. W., Bauman, K. E., Harris, K. M., Jones, J., ... Udry, J. R. (1997). Protecting adolescents from harm, findings from the national longitudinal study on adolescent health. Journal of the American Medical Association, 278(10), 823832. doi:10.1001/jama.1997.03550100049038

Ribeiro, J. L. P. (2001). Mental Health Inventory: Um estudo de adaptação à população Portuguesa [Mental Health Inventory: Adaptation study to the Portuguese population]. Psicologia, Saúde \& Doenças, 2(1), 77-99.

Rivers, I. (2001). The bullying of sexual minorities at school: Its nature and long-term correlates. Educational and Child Psychology, 18(1), 32-46. 
Rivers, I. (2004). Recollections of bullying at school and their long-term implications for lesbians, gay men, and bisexuals. Crisis: The Journal of Crisis Intervention and Suicide Prevention, 25(4), 169-175. doi:10.1027/0227-5910.25.4.169

Rivers, I., \& Carragher, D. J. (2003). Social-developmental factors affecting lesbian and gay youth: A review of cross-national research findings. Children \& Society, 17, 374-385. doi:10.1002/CHI.771

Robinson, J. P., \& Espelage, D. L. (2012). Bullying explains only part of LGBTQ-heterosexual risk disparities: Implications for policy and practice. Educational Researcher, 41(8), 309319. doi:10.3102/0013189X12457023

Rodrigues, L., Brás, A., Cunha, C., Petiz, J. P., \& Nogueira, C. (2015). Teachers' discourses on young lesbians in the portuguese school context. Actualidades Investigativas En Educación, 15(2), 1-19. doi:10.15517/aie.v15i2.18535

Russell, S., Ryan, C., Toomey, R., Diaz, R., \& Sanchez, J. (2011). Lesbian, gay, bisexual, and transgender adolescent school victimization: Implications for young adult health and adjustment. Journal of School Health, 81(5), 223-230. doi:10.1111/j.17461561.2011 .00583

Russell, S. T., Clarke, T. J., \& Clary, J. (2009). Are teens “post-gay”? Contemporary adolescents' sexual identity labels. Journal of Youth and Adolescence, 38, 884-890. doi:10.1007/s10964-008-9388-2

Russell, S. T., Toomey, R. B., Ryan, C., \& Diaz, R. M. (2014). Being out at school: The implications for school victimization and young adult adjustment. American Journal of Orthopsychiatry, 84(6), 635-643. doi:10.1037/ort0000037 
Ryan, C., Huebner, D., Diaz, R. M., \& Sanchez, J. (2009). Family rejection as a predictor of negative health outcomes in white and Latino lesbian, gay, and bisexual young adults. Pediatrics, 123(1), 346-52. doi:10.1542/peds.2007-3524

Ryan, C., Russell, S., Huebner, D., Diaz, R., \& Sanchez, J. (2010). Family acceptance in adolescence and the health of LGBT young adults. Journal of Child and Adolescent Psychiatric Nursing, 23(4), 205-13. doi:10.1111/j.1744-6171.2010.00246.x

Saewyc, E. M. (2011). Research on adolescent sexual orientation: Development, health disparities, stigma, and resilience. Journal of Research on Adolescence, 21(1), 256-272. doi:10.1111/j.1532-7795.2010.00727.x

Savin-Williams, R. C. (2003). Lesbian, gay, and bisexual youths' relationships with their parents. In L. D. Garnets \& D. C. Kimmel (Eds.) Psychological perspectives on lesbian, gay, and bisexual experiences (pp. 299-326). New York: Columbia University Press

Savin-Williams, R. C., \& Dubé, E. M. (1998). Parental reactions to their child's disclosure of a gay/lesbian identity. Family Relations, 47(1), 7-13. Retrieved from http://www.jstor.org/stable/10.2307/584845

Savin-Williams, R. C., \& Ream, G. L. (2007). Prevalence and stability of sexual orientation components during adolescence and young adulthood. Archives of Sexual Behavior, 36, 385-394. doi:10.1007/s10508-006-9088-5

Savin-Williams, R., \& Diamond, L. M. (2000). Sexual identity trajectories among sexualminority youths: gender comparisons. Archives of Sexual Behavior, 29(6), 607-27. Retrieved from http://www.ncbi.nlm.nih.gov/pubmed/11100265 
Scheier, M. F., \& Carver, C. S. (1985). Optimism, coping, and health: assessment and implications of generalized outcome expectancies. Health Psychology, 4(3), 219-247. doi:10.1037/0278-6133.4.3.219

Shanahan, L., McHale, S. M., Crouter, A. C., \& Osgood, D. W. (2007). Warmth with mothers and fathers from middle childhood to late adolescence: within- and between-families comparisons. Developmental Psychology, 43(3), 551-563. doi:10.1037/0012-1649.43.3.551

Smetana, J. G., Campione-Barr, N., \& Metzger, A. (2006). Adolescent development in interpersonal and societal contexts. Annual Review of Psychology, 57, 255-84. doi:10.1146/annurev.psych.57.102904.190124

Ueno, K. (2005). Sexual orientation and psychological distress in adolescence: Examining interpersonal stressors and social support processes. Social Psychology Quarterly, 68, 258277. doi:10.1177/019027250506800305

Veit, C. T., \& Ware, J. E. (1983). The structure of psychological distress and well-being in general populations. Journal of Consulting and Clinical Psychology, 51(5), 730-742. doi:10.1037/0022-006X.51.5.730

Walsh, F. (2003). Family resilience: A framework for clinical practice. Family Process, 42(1), 1-18. doi:10.1111/j.1545-5300.2003.00001.x

Williams, D. R., Yu, Y., Jackson, J. S., \& Anderson, N. B. (1997). Racial differences in physical and mental health. Journal of Health Psychology, 2(3), 335-351. doi:10.1177/135910539700200305

WHO (2014). Mental health: a state of well-being. Retrieved in February 2015 from: http://www.who.int/features/factfiles/mental_health/en/ 
Table 1

Discrimination, Familial Optimism and Family Relationships in Low and High Mental Health Youth

\begin{tabular}{|c|c|c|c|c|}
\hline & $\begin{array}{c}\text { Total sample } \\
\text { M (SD) }\end{array}$ & $\begin{array}{c}\text { Low Mental Health } \\
\text { M (SD) }\end{array}$ & $\begin{array}{c}\text { High Mental Health } \\
\text { M (SD) }\end{array}$ & Between-group difference \\
\hline \multicolumn{5}{|c|}{ Perception of Discrimination: Pillai's trace $=0.16, F(2,62)=12.00, p=.004, \eta_{p}^{2}=.16, \pi=0.87$} \\
\hline Unfair Treatment & $1.18(1.08)$ & $1.48(1.22)^{* *}$ & $0.70(0.84)^{* *}$ & $F(1,63)=9.27^{* *}, \eta_{p}^{2}=.13$ \\
\hline Personal Rejection & $1.30(1.08)$ & $1.66(1.09)^{* *}$ & $0.86(0.92)^{* *}$ & $F(1,63)=10.37^{* *}, \eta_{p}^{2}=.14$ \\
\hline Familial Optimism & $3.47(0.70)$ & $3.33(0.75)^{*}$ & $3.69(0.60)^{*}$ & $F(1,62)=4.56^{*}, \eta^{2}=.07$ \\
\hline \multicolumn{5}{|c|}{ Satisfaction in relationships: Pillai's trace $=0.04, F(2,56)=1.13, p=.331, \eta_{p}^{2}=.04, \pi=0.24$} \\
\hline Mother & $3.66(1.07)$ & $3.54(1.03)$ & $3.78(1.19)$ & $F(1,57)=0.67, \eta_{p}^{2}=.01$ \\
\hline Father & $3.50(1.22)$ & $3.31(1.31)$ & $3.72(1.12)$ & $F(1,57)=1.68, \eta_{p}^{2}=.03$ \\
\hline \multicolumn{5}{|c|}{ Intimacy in relationships: Pillai's trace $=0.04, F(2,56)=1.24, p=.297, \eta_{p}^{2}=.04, \pi=0.26$} \\
\hline Mother & $2.72(1.28)$ & $2.71(1.27)$ & $2.81(1.30)$ & $F(1,57)=0.143, \eta_{p}^{2}=.00$ \\
\hline Father & $2.05(1.06)$ & $1.81(1.04)$ & $2.24(1.02)$ & $F(1,57)=2.71, \eta_{p}^{2}=.04$ \\
\hline \multicolumn{5}{|c|}{ Admiration in relationships: Pillai's trace $=0.09, F(2,56)=2.62, p=.081, \eta_{p}{ }^{2}=.09, \pi=0.50$} \\
\hline Mother & $3.62(1.05)$ & $3.48(1.00)$ & $3.89(1.08)$ & $F(1,57)=2.43, \eta_{p}^{2}=.04$ \\
\hline Father & $3.38(1.09)$ & $3.10(1.19)^{*}$ & $3.73(1.04)^{*}$ & $F(1,57)=4.62 *, \eta_{p}^{2}=.08$ \\
\hline \multicolumn{5}{|c|}{ Conflict in relationships: Pillai's trace $=0.13, F(2,56)=4.18, p=.020, \eta_{p}^{2}=.13, \pi=0.71$} \\
\hline Mother & $3.15(0.90)$ & $3.33(0.84)^{*}$ & $2.81(0.99)^{*}$ & $F(1,57)=4.76^{*}, \eta_{p}^{2}=.08$ \\
\hline Father & $2.91(1.05)$ & $3.08(0.83)^{*}$ & $2.49(1.09)^{*}$ & $F(1,57)=5.44^{*}, \eta_{p}{ }^{2}=.09$ \\
\hline
\end{tabular}


Table 2

Intercorrelations Among Variables

\begin{tabular}{|c|c|c|c|c|c|c|c|c|c|c|c|}
\hline & 1 & 2 & 3 & 4 & 5 & 6 & 7 & 8 & 9 & 10 & 11 \\
\hline \multicolumn{12}{|l|}{ 1. Mental Health Inventory } \\
\hline 2. Unfair Treatment & $-.39^{* *}$ & & & & & & & & & & \\
\hline 3. Personal Rejection & $-.43^{* *}$ & $.60^{* *}$ & & & & & & & & & \\
\hline 4. Familial Optimism & $.30^{* *}$ & -.13 & -.20 & & & & & & & & \\
\hline 5. Satisfaction w. Mother & .13 & -.12 & -.17 & $.26^{*}$ & & & & & & & \\
\hline 6. Satisfaction w. Father & .13 & .10 & .06 & .16 & .06 & & & & & & \\
\hline 7. Intimacy w. Mother & .03 & -.04 & -.13 & $.34^{* *}$ & $.41^{* *}$ & .02 & & & & & \\
\hline 8. Intimacy w. Father & .15 & .08 & .04 & .17 & .01 & $.57^{* *}$ & $.23^{*}$ & & & & \\
\hline 9. Admiration w. Mother & .15 & -.09 & $-.27^{*}$ & $.36^{* *}$ & $.65^{* *}$ & .09 & $.59^{* *}$ & .14 & & & \\
\hline 10. Admiration w. Father & $.23^{*}$ & .09 & -.06 & $.27^{*}$ & .14 & $.77^{* *}$ & .10 & $.68^{* *}$ & $.337^{* *}$ & & \\
\hline 12. Conflict w. Mother & $-.31^{* *}$ & $.26^{*}$ & .22 & $-.27^{*}$ & $-.58^{* *}$ & -.01 & -.21 & -.02 & $-.47^{* *}$ & -.10 & \\
\hline 12. Conflict w. Father & $-.29^{* *}$ & .20 & .04 & -.18 & .13 & $-.39^{* *}$ & .01 & $-.25^{*}$ & .02 & $-.34^{* *}$ & $.20^{*}$ \\
\hline
\end{tabular}




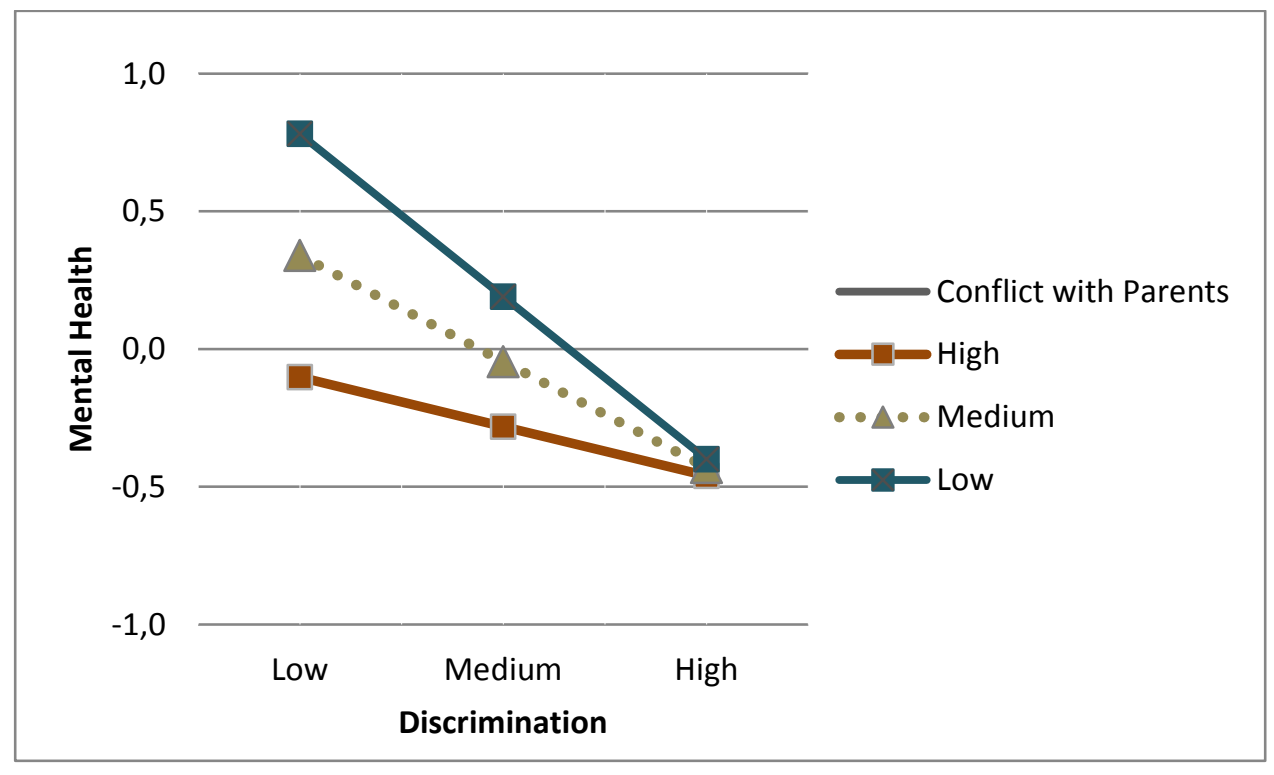

Figure 1. Conflict with Parents as Moderator of the Effects of Discrimination on Mental Health 